\title{
Ecological Environment Changes of Mining Areas Around Nansi Lake With Remote Sensing Monitoring
}

Hu Liu

Shandong University of Science and Technology

Yan Jiang

Shandong University of Science and Technology

Rafal Misa

Polish Academy of Sciences

Junhai Gao

China Coal Technology and Engineering Group Corp Tangshan Research Institute Co., Ltd

Mingyu Xia

Shandong University of Science and Technology

Axel Preusse

RWTH Aachen University

Anton Sroka

Polish Academy of Sciences

Yue Jiang ( $\sim$ jiangyue@cumt.edu.cn )

China University of Mining and Technology https://orcid.org/0000-0002-5606-7138

\section{Research Article}

Keywords: Nansi lake, Coal mining, Mine ecological environment, Remote sensing monitoring,

Environmental change

Posted Date: February 16th, 2021

DOl: https://doi.org/10.21203/rs.3.rs-186720/v1

License: (c) (i) This work is licensed under a Creative Commons Attribution 4.0 International License. Read Full License

Version of Record: A version of this preprint was published at Environmental Science and Pollution Research on April 12th, 2021. See the published version at https://doi.org/10.1007/s11356-021-13849-y. 


\section{Ecological environment changes of mining areas around Nansi lake with remote sensing monitoring}

Hu Liu ${ }^{1}$, Yan Jiang ${ }^{1}$, Rafal Misa ${ }^{2}$, Junhai Gao ${ }^{3}$, Mingyu Xia ${ }^{1}$, Axel Preusse ${ }^{4}$, Anton Sroka $^{2}$, Yue $\operatorname{Jiang}^{5 *}$

1. College of Geodesy and Geomatics, Shandong University of Science and Technology, China

2. Strata Mechanics Research Institute, Polish Academy of Sciences, Poland

3. China Coal Technology \& Engineering Group Tangshan Research Institute Co., Ltd, China

4. Institute for Mine Surveying, Mining Subsidence Engineering and Geophysics in Mining, RWTH Aachen University, Germany

5. School of Environment and Spatial Informatics, China University of Mining and Technology, China

* Yue Jiang; jiangyue@ @umt.edu.cn (Ya.J.); Tel.: +86 532-86057270.

Abstract Underground mining activity has existed for more than 100 years in Nansi lake. Coal mining not only plays a supporting role in local social and economic development but also has a significant impact on the ecological environment in the region. Landsat series remote sensing data (1988 2019) are used to research the impact of coal mining on the ecological environment in Nansi lake. Then Support Vector Machine (SVM) classifier is applied to extract the water area of the upstream lake from 1988 to 2019, and ecological environment and spatiotemporal variation characteristics are analyzed by Remote Sensing Ecology Index (RSEI). The results illustrate that the water area change is associated with annual precipitation. Compared with 2009, the ecological quality of the lake is worse in 2019 , and then the reason for this change is due to large-scale underground mining. Therefore, the coal mines from the natural reserve may be closed or limited to the mining boundary for protecting the lake's ecological environment.

Keywords Nansi lake; Coal mining; Mine ecological environment; Remote sensing monitoring; Environmental change 


\section{Introduction}

Nansi lake is located in the southwest of Shandong Province, China $\left(34^{\circ} 27^{\prime} \mathrm{N}\right.$ to $35^{\circ} 20^{\prime} \mathrm{N}$ and $116^{\circ} 34^{\prime} \mathrm{E}$ to $\left.117^{\circ} 24^{\prime} \mathrm{E}\right)$, which is composed of Nanyang lake, Dushan lake, Zhaoyang lake, and Weishan lake. Nansi lake is the largest freshwater lake in Shandong Province and the sixth-largest freshwater lake in China (the water area is $1266 \mathrm{~km}^{2}$ ). Also, the northern terrain of Nansi lake is higher than the southern terrain, the length is $125 \mathrm{~km}$ from north to south, the width is 5.6 to $30 \mathrm{~km}$ from east to west, the average water depth is $1.5 \mathrm{~m}$, and the maximum water depth is $6 \mathrm{~m}$. Nansi lake lies within a warm temperate humid monsoon climate (Liang 2014), which benefits a diversity of plant and animal species including 539 species of vascular plants, 337 species of vertebrates, and 221 species of birds in the lake area. Moreover, the lake area is an important habitat and breeding place for many rare and endangered birds, as well as an important migration and resting place for migratory birds in spring and autumn. Moreover, Nansi lake was established as a provincial nature reserve by the government in 2003, and then the government adjusted the scope and functional areas of the Nansi lake provincial nature reserve in 2019 (Fig. 1). The current area is larger than the original after adjustment, the total area is $1116.51 \mathrm{~km}^{2}$ and the core zone is $451.15 \mathrm{~km}^{2}$, which accounts for $40.41 \%$ of the total area. 


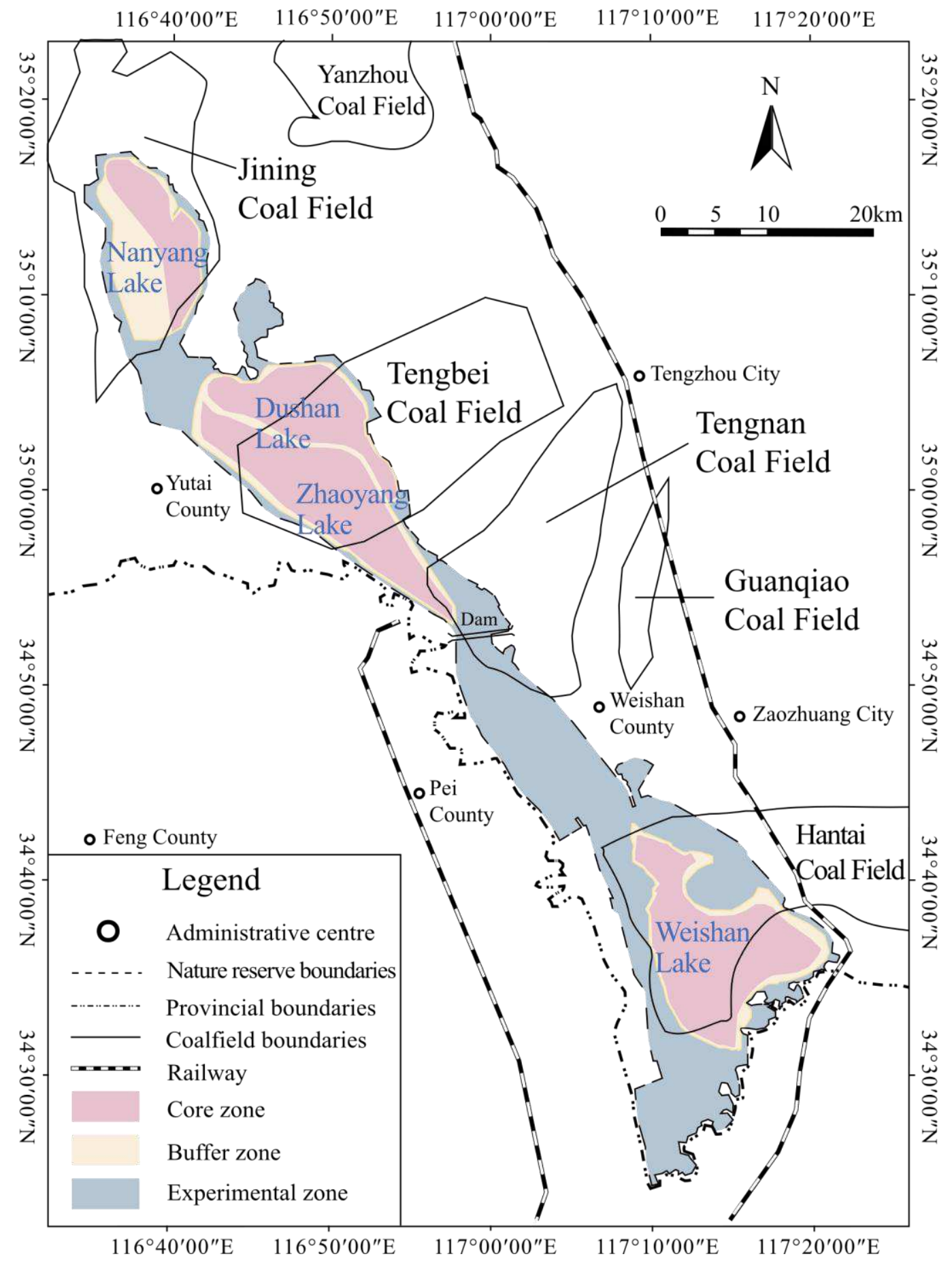

Fig. 1 Distribution of Nansi lake nature reserve and coal resources

Abundant coal resources exist around the Nansi lake area, and people mine coal resources for more than 100 years. In the past two decades, the lake area has been an important energy production 51 base, the coal production accounts for $15 \%$ of the total coal production in Shandong Province. The underground mining can destroy the original strata stress balance, which leads to the collapse, fracture, and bending from the bottom to the top. The surface can subside due to the underground mining 
influence (Den et al. 2015; Jiang et al. 2019). There is a long history of the impact of surface subsidence on the land environment (Kratzsch 1974; Reddish and Whittaker 1989). However, the research of water ecological environment damage caused by underground mining is insufficient. Most researches believe the two viewpoints: (1) Underground mining can not cause surface water to leak into the mine, and underground mining has no direct impact on surface water; (2) The subsidence caused by mining can increase the water depth, expand the water storage capacity, decrease the speed of sediment siltation, and also benefit for irrigation, shipping, aquaculture, etc. (Ma et al. 2019; Shu 1992; Zhang et al. 2018). The surface subsidence can change the original topography of the lake area and the ecological environment (a non-pollution hazard to the lake area ecology). On the one hand, researchers always concentrate on the safeguard of coal mine and maximum utilization of coal resource and form mature safety measures for underwater mining (Teng et al. 2012). On the other hand, researchers focus on the destruction law of strata (Sui and Xu 2013; Xu and Sui 2013), but they hardly consider the impact of underground mining on the ecological environment. However, environmental supervision departments pay attention to gangue and mine water discharge (Wang et al. 2016) and hardly focus on the relationship between coal mining and the water ecosystem. At present, the ecological effect of coal mining on the environment of Nansi lake is not clear, so it is necessary to research this issue.

The surface subsidence caused by coal mining is a time process, so the impact of mining subsidence on the environment is a cumulative process, which can not be found in a short time. Therefore, the long-term remote sensing data from 1988 to 2019 are used to assess the ecological environment quality of the lake area with the Remote Sensing Ecological Index (RSEI). The cumulative influence of coal mining on the ecological environment can be indirectly reflected. Finally, it provides a quantitative scientific basis for evaluating the impact of coal mining on Nansi lake.

\section{Materials and methods}

\section{Research area}

Nansi lake is divided into upstream lake and downstream lake by the dam. The research area is located in the upstream lake that is composed of three lakes (Nanyang lake, Dushan lake, and Zhaoyang lake) (Fig. 2). The coal-bearing area in the lake is $1789 \mathrm{~km}^{2}$, and the average thickness is $11 \mathrm{~m}$ (Li and Jiang 2003). More than 40 mines exist in Nansi lake after decades of exploration and development, Jining, Tengnan, and Tengbei coal fields are located in the research area. 
Fig. 2 Location of Nansi Lake (2019 Landsat-8 OLI image)

\section{Data acquisition and preprocessing}

The main data sources are the Landsat series of remote sensing images, which are freely obtained from the U.S. Geological Survey (https://earthexplorer.usgs.gov/), Landsat-5 TM data are from 1988 2005, 2010, and 2011; Landsat-7 ETM data are from 2006 2009; Landsat-8 OLI/TIRS data are from 2012, and 2013 2019. The time of these images is selected in August or September due to less cloud cover and fair weather. Generally, the recent images (2019) are chosen to be the registration benchmark, and the accuracy is controlled within 0.5 pixels. Finally, pretreatments such as radiometric calibration, atmospheric correction, and image cropping are implemented.

\section{Extraction of water area}

Support Vector Machine (SVM) classifier is used to extract the upstream lake water area of Nansi lake. Compared with other automatic extraction methods of single band threshold, the SVM classification method can sufficiently apply the abundant spectral information and geometric texture 
101 information, and the extraction accuracy of the water body is higher than that of other methods. SVM 102 is a kind of generalized linear classifier with a binary classification of supervised learning (Gold and 103 Sollich 2003). It is widely used in remote sensing image classification and other information extraction. 104 The classification principle is that apply a hyperplane as the decision boundary, which can achieve correct classification and maximize the classification interval.

The SVM classification method mainly uses two bands of remote sensing data to extract water: (1) the near-infrared band $(0.76 \sim 0.90 \mu \mathrm{m})$, in the strong absorption zone of the water body, which is applied to define the water boundary, and identify the geological structure and landform related to water; (2) the far-infrared band $(2.08 \sim 2.35 \mu \mathrm{m})$, in the strong absorption zone of the water body, the water area appears black in this band. In addition, SVM also combines texture information to distinguish the boundaries of the lake, fish ponds, and paddy fields. The overall accuracy of classification is $85 \%$, and the kappa coefficient (an index to measure the accuracy of classification, it has five different levels to define uniformity, the result is almost perfect between 0.81 and 1.0) is 0.82 . This result illustrates SVM is significant and high precision for extracting lake water area.

\section{Construction of Remote Sensing Ecology Index (RSEI)}

The Ministry of Environmental Protection of China promulgated the latest revision of the Technical Criterion for Ecosystem Status Evaluation (China MEE 2015) in March 2015. The Ecological Index (EI) from this criterion has five evaluating indicators including biological richness, vegetation coverage, water network density, land degradation, and pollution load. The indicators of biological richness, vegetation coverage, water network density can be obtained easily by remote sensing, but the last two indicators are more difficult to gain by remote sensing. Besides, the weights of the five indicators are determined by a human, which has a certain subjective deviation. However, Remote Sensing Ecology Index (RSEI) applies four indicators of greenness, humidity, dryness, and heat to define the weight of each indicator with principal component analysis, and RSEI can avoid human subjective deviation. The greenness is similar to the biological richness, vegetation coverage from the criterion due to the similar calculation method. Humidity is similar to water network density, it can represent not only lakes and rivers but also the humidity of vegetation and soil. Dryness is related to land degradation, so the bare soil can express dryness. The higher value of bare soil shows more serious land degradation. The surface temperature (heat) is related to urban expansion and other 
environmental changes.

Remote Sensing Ecological Index (RSEI) applies to perform principal component analysis (PCA) for the four components of wetness (Wet), greenness (FVC), dryness (NDBSI), and heat (LST), and then the first principal component (PC1) is normalized to generate RSEI. PCA is a statistical analysis method in which multiple variables convert to minorities of principal components with dimensionality reduction technology ( $\mathrm{Du}$ and Fowler 2007). These principal components can reflect most of the information of the original variables, and they are usually expressed as some linear combination of the original variables.

Greenness (FVC): Fractional Vegetation Cover (FVC) refers to the percentage of the vertical projection area of vegetation on the ground (including leaves, stems, and branches) in a unit area to the total area of the statistical area (Zhou et al. 2006). Therefore, FVC can be used to indicate the greenness:

$$
\begin{gathered}
F V C=\frac{N D V I-N D V I_{\text {soil }}}{N D V I_{\text {veg }}-N D V I_{\text {soil }}} \\
N D V I=\left(\rho_{N I R}-\rho_{R}\right) /\left(\rho_{N I R}+\rho_{R}\right)
\end{gathered}
$$

where

NDVI- normalized vegetation index; $N D V I_{\text {soil }}-N D V I$ value of bare soil or no vegetation cover area; $N D V I_{\text {veg- }}$ the $N D V I$ value of the vegetation cover area; $\rho_{N I R^{-}}$spectral reflectance of the near-infrared band; $\rho R^{-}$spectral reflectance of the red band

Wetness (Wet): the wetness index reflects the humidity of water, soil, and vegetation, which is closely related to the ecological environment (Crist 1985; Huang et al. 2002; Todd and Hoffer 1998). The Landsat-5 TM data, Landsat-7 ETM data, and Landsat-8 OLI/TIRS data can be respectively calculated by equation (3), (4), and (5).

$$
W e t=0.0315 \rho_{B}+0.2021 \rho_{G}+0.3102 \rho_{R}+0.1594 \rho_{\text {NIR }}-0.6806 \rho_{\text {SWIR }_{1}}-0.6109 \rho_{\text {SWIR }_{2}}
$$




$$
\begin{aligned}
& W e t=0.2626 \rho_{B}+0.2141 \rho_{G}+0.0926 \rho_{R}+0.0656 \rho_{\text {NIR }}-0.7629 \rho_{\text {SWIR }_{1}}-0.5388 \rho_{\text {SWIR }_{2}} \\
& W e t=0.1511 \rho_{B}+0.1973 \rho_{G}+0.3283 \rho_{R}+0.0 .3407 \rho_{\text {NIR }}-0.7117 \rho_{\text {SWIR }}-0.4559 \rho_{\text {SWIR }_{1}}
\end{aligned}
$$

155

156

where

$\rho_{B^{-}}$spectral reflectance of the blue band; $\rho_{G}$ - spectral reflectance of the green band; $\rho_{R}$ - spectral reflectance of the red band; $\rho_{N I R^{-}}$spectral reflectance of the near-infrared band; $\rho_{S W I R}{ }^{-}$spectral $^{-}$ reflectance of the mid-infrared band; $\rho_{S W I R_{2}}-$ spectral reflectance of the far-infrared band

Dryness (NDBSI): the dryness index consists of the average of the building index (IBI) (Xu 2008) and the bare soil index (SI) (Rikimaru et al. 2002):

$$
\begin{gathered}
N D B S I=\frac{I B I+S I}{2} \\
I B I=\frac{\frac{2 \rho_{S W I R_{1}}}{\rho_{S W I R_{1}}+\rho_{\text {NIR }}}-\frac{\rho_{N I R}}{2 \rho_{S W I R_{1}}}+\frac{\rho_{G}}{\rho_{N I R}+\rho_{R}}+\frac{\rho_{\text {NIR }}}{\rho_{G}+\rho_{S W I R_{1}}}}{\rho_{\text {NII }}+\rho_{R}}+\frac{\rho_{G}}{\rho_{G}+\rho_{S W I R_{1}}} \\
S I=\frac{\left(\rho_{\text {NIR }}\right.}{\left(\rho_{\text {SWIR }_{1}}+\rho_{R}\right)-\left(\rho_{\text {NIR }}+\rho_{B}\right)}
\end{gathered}
$$

Where

$\rho_{B^{-}}$spectral reflectance of the blue band; $\rho_{G}$ - spectral reflectance of the green band; $\rho_{R}$ - spectral reflectance of the red band; $\rho_{N I R^{-}}$spectral reflectance of the near-infrared band; $\rho_{S W_{I}{ }_{1}}{ }^{-}$spectral reflectance of the mid-infrared band

Heat (LST): The heat index is expressed by the land surface temperature (LST), and its calculation model (Nichol 2005) is following:

$$
\begin{aligned}
& L S T=T /[1+(\lambda T / \rho) \ln \varepsilon] \\
& T=K_{2} / \ln \left(K_{1} / L_{T I R}+1\right)
\end{aligned}
$$


174 where

$175 L S T$ - land surface temperature; $T$ - temperature of the sensor, $\lambda$ - central wavelength of the thermal 176 infrared band; $\rho$ - calculation parameter $\left(1.438 \times 10^{-2} \mathrm{~m} \cdot \mathrm{K}\right) ; \varepsilon$ - land surface emissivity (it can be calculated by NDVI with Sobrino's model) (Sobrino et al. 2004); LTIR- the radiation of TM, ETM, and TIRS thermal infrared band; $K_{1}$ and $K_{2}$ - calibration parameters standardized before the principal component analysis (Fig. 3). The RSEI result shows the larger value, 182 the better the ecological quality.

\section{Results and discussion}

\section{Water area change}

The SVM classification method was used to extract the water area of upstream Nansi lake from 1988 to 2019 (Fig. 4). According to the change information of remote sensing monitoring, the water areas (blue parts) in 1988 and 2000 were extremely smaller than that of other years (Fig. 4a and 4e),

192 Nanyang and Zhaoyang lakes almost dried up due to severe drought from 1987 to 1989 and 2000 to 1932002 (Meng and Dong 2019). The water level of the upstream lake dropped to the lowest level in 194 history, and the lake water basically dried up. The water areas decreased every year and appeared 
fragmented shapes around the lake boundary.

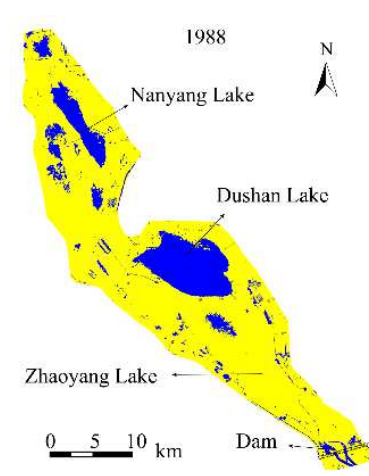

(a)

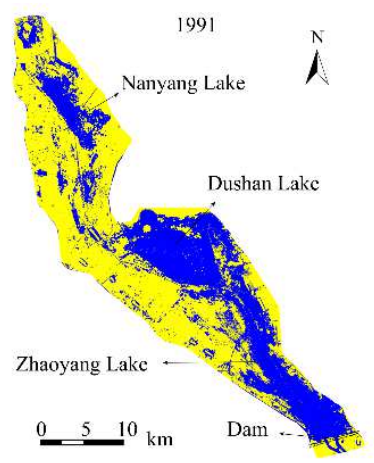

(b)

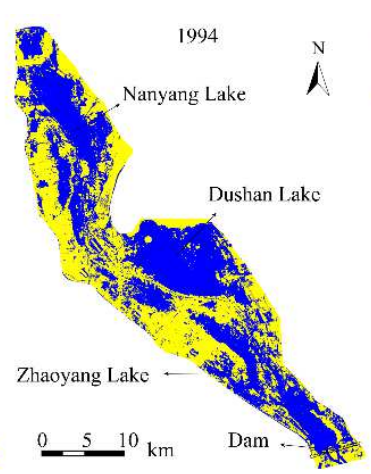

(c)

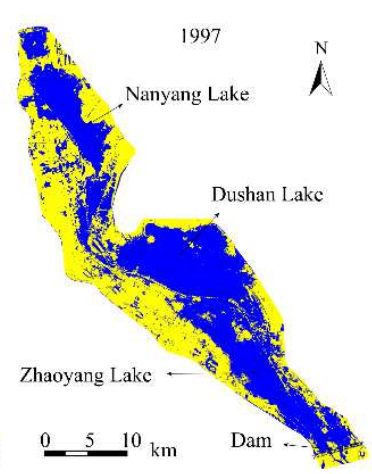

(d)

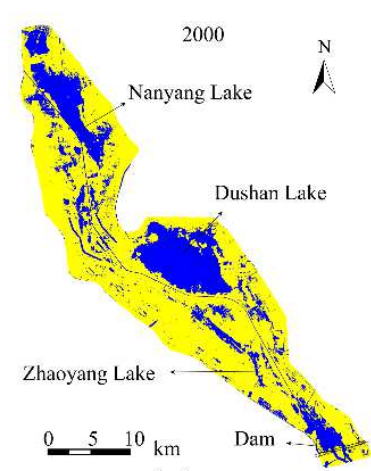

(e)

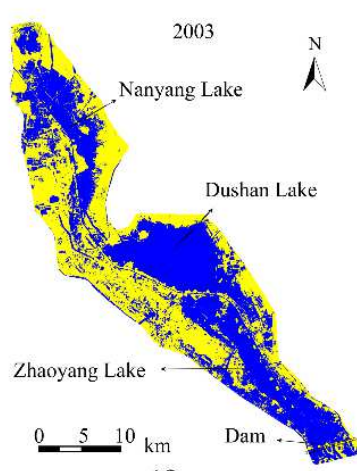

(f)

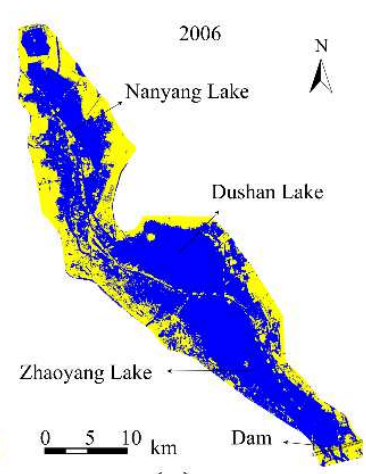

(g)

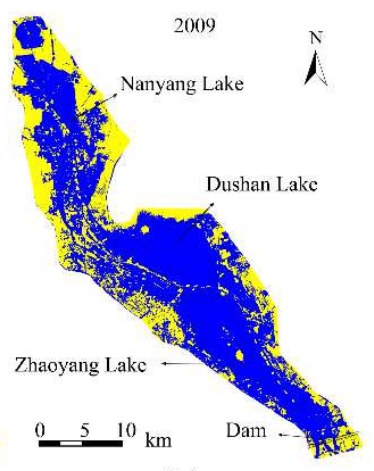

(h)

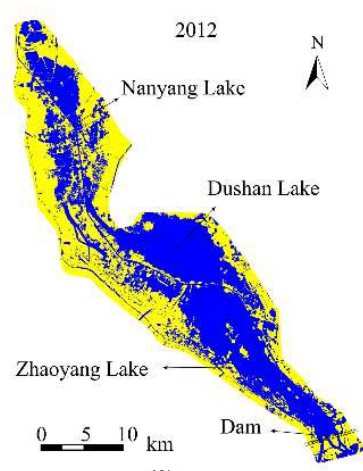

(i)

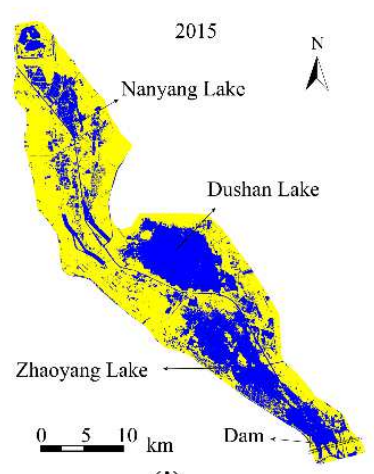

(j)

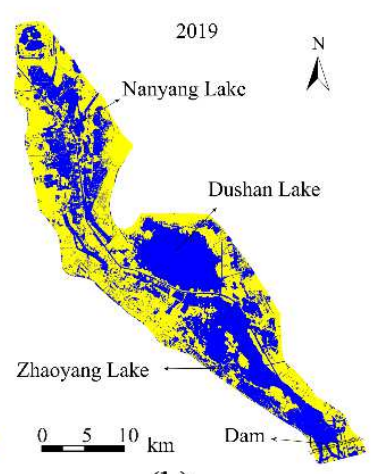

(k)

In addition, extracted water area data and average precipitation (from 1988 to 2019) were used to objectively assess the water area change. The trends of water area change (red line) and average precipitation (blue line) are identical in Fig. 5. This result illustrates that the trend of water area change is consistent with that of average precipitation in the last thirty years. 


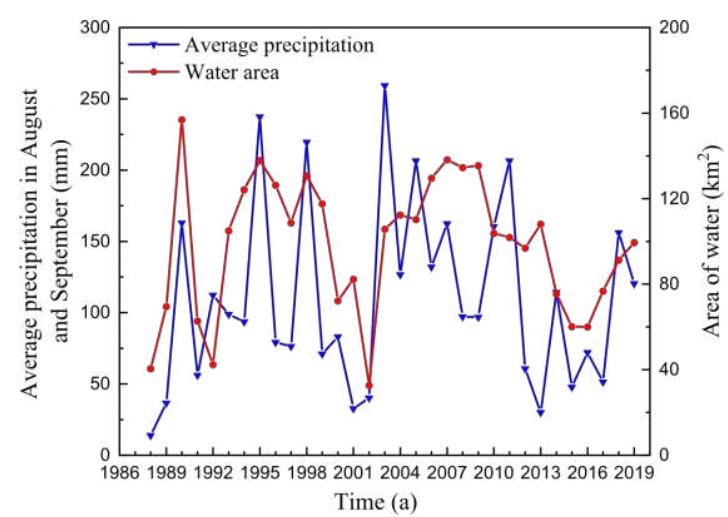

(a) Nanyang Lake

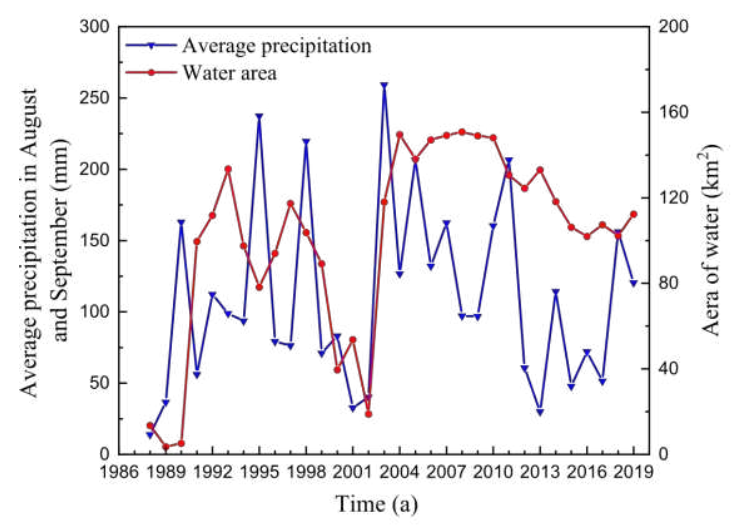

(c) Zhaoyang Lake

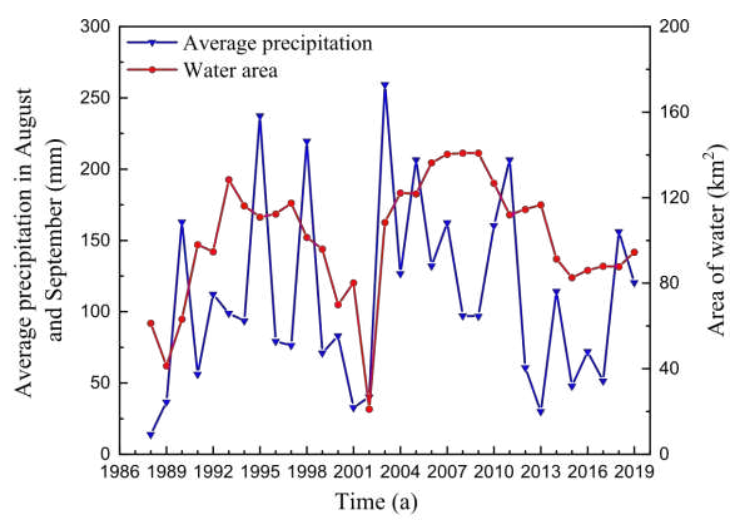

(b) Dushan Lake

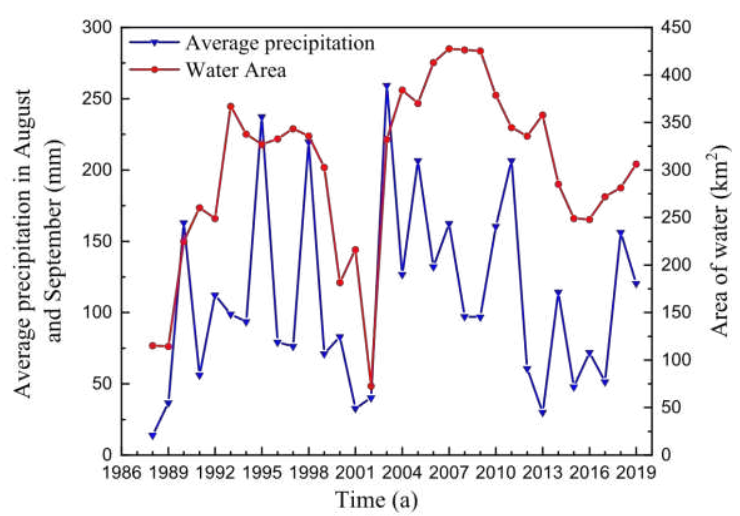

(d) The Upstream Lake

Fig. 5 The trends of water area and average precipitation

Therefore, it seems that underground mining in Jining and Tengbei coal fields has barely influence on the lake water area, instead, the water area change is related to the precipitation. However, the water area may be affected by the extension of underground mining to the lake. The total overlapping area of these two coal fields and the lake is $398 \mathrm{~km}^{2}$, which is about $66 \%$ of the lake area. According to estimate, the subsidence volume of the lake bottom will be $1.94 \times 10^{9} \mathrm{~m}^{3}$ after accomplish mining of two coal fields, but the lake storage capacity is only $9.03 \times 10^{8} \mathrm{~m}^{3}$, namely that most of the lake water will flow into the subsidence area, and the shallow water may no longer exist. Finally, this phenomenon can make a significant reduction in the water area.

\section{Analysis of RSEI indexes}

According to the weights of four RSEI indexes (Table 1), the average RSEI increased from 0.583 to 0.632 between 1988 and 2009 (increased by 8.4\%). However, the average RSEI decreased from 0.632 to 0.584 between 2009 and 2019 (decreased by 7.59\%). RSEI appears a trend of the slow rise and then a sharp decline in this research area. This trend illustrates that the ecological environment 
222 gets better and then gets worse. Moreover, PC1 loads of wet and FVC have a positive influence on the 223 ecological environment, but PC1 loads of NDBSI and LST have a negative influence on the ecological 224 environment (positive number: beneficial; negative number: harmful). The contributions of wet and 225 FVC show a reduced trend, but that of NDBSI and LST appear to a rising trend. These trends illustrate vegetation coverage and construction land have a significant effect on the ecological environment, and then the decline of vegetation coverage and increase of construction land make the ecological environment worse.

Table 1 Statistics of factor indicators and Remote Sensing Ecological Index

\begin{tabular}{ccccccccc}
\hline \multirow{2}{*}{ Indexes } & \multicolumn{2}{c}{1988} & \multicolumn{2}{c}{1998} & & 2009 & 2019 \\
\cline { 2 - 8 } & Average & PC1 load & Average & PC1 load & Average & PC1 load & Average & PC1 load \\
\hline Wet & 0.546 & 0.182 & 0.679 & 0.179 & 0.630 & 0.181 & 0.662 & 0.153 \\
FVC & 0.719 & 0.574 & 0.747 & 0.581 & 0.729 & 0.563 & 0.691 & 0.461 \\
NDBSI & 0.568 & -0.551 & 0.560 & -0.543 & 0.493 & -0.572 & 0.366 & -0.669 \\
LST & 0.338 & -0.412 & 0.388 & -0.402 & 0.433 & -0.542 & 0.405 & -0.631 \\
RESI & 0.583 & & 0.587 & & 0.632 & & 0.584
\end{tabular}

\section{Dynamic changes of ecological environment}

RSEI is divided into five levels for the change analysis of ecological environment: Poor (0 0.2),

234 Fair (0.2 0.4), Moderate (0.4 0.6), Good (0.6-0.8), Excellent (0.8 1.0) (Table 2).

Table 2 Ecological environment classification

\begin{tabular}{ll}
\hline RSEI Level & Description \\
\hline Poor $(0 \sim 0.2)$ & Severe natural ecological conditions, prominent ecological \\
& environmental problems, and extremely fragile ecological \\
& functions. \\
& Less vegetation coverage, fewer species, obvious ecological \\
& environmental problems, fragile ecological functions, and \\
& obvious factors limiting human activities.
\end{tabular}


Moderate vegetation coverage, general biodiversity, general

Moderate (0.4 0.6)

Good $(0.6 \sim 0.8)$ natural ecological conditions, certain ecological environmental

problems, and relatively fragile ecological functions.

Relatively high vegetation coverage, relatively abundant

biodiversity, relatively good natural ecological condition,

relatively stable ecological function, and certain ecological

environmental problems.

High vegetation coverage, relatively abundant biodiversity,

superior natural ecological condition, high ecosystem carrying

capacity, stable ecosystem, and strong self-regulation ability. worse than that of the west from 1988 to 2019 (Fig. 6). The main reason may low mountains and hills and serious soil erosion exist in the northeast (Ge et al. 2012). In the recent thirty years, the ecological environment of the northeast is better than before, which is related to afforestation and other beneficial activities of improving soil erosion. In addition, underground mining activities exist in the coal fields of the southeast for many years (Fig. 7), which can make surface subsidence of some areas. The surface subsidence can reduce the original covers of farmland, grassland, and woodland (Liang 2014; Meng and Dong 2019), and then cause a series of environmental problems. The level of ecological environment changes from excellent to fair or poor, ecological environmental problems and ecological function are more fragile. The ecological environment of the western area is better than that of the eastern area, but some poor areas appear an expansion trend in the western area. This phenomenon is probably caused by an increase in urban construction land (Liu et al. 2020). 


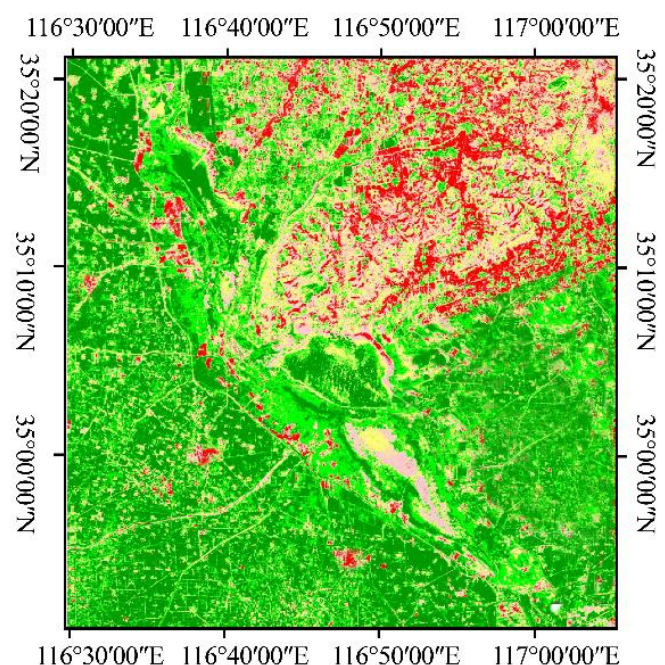

(a) 1988

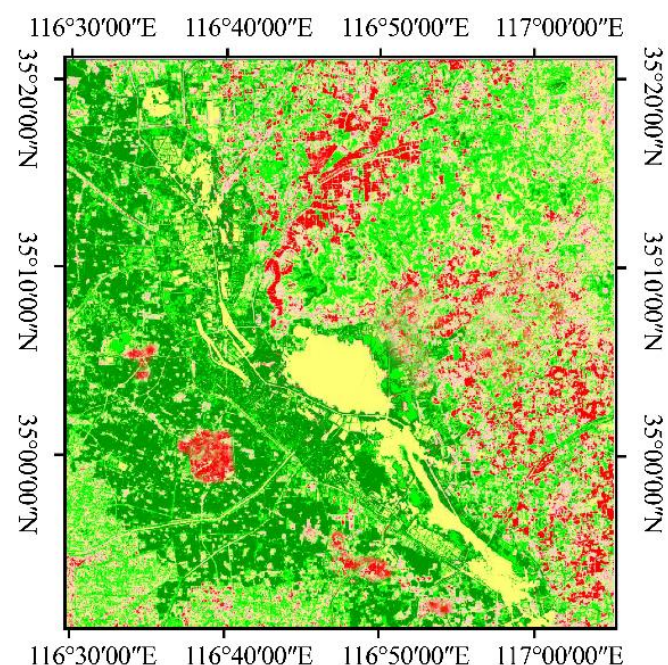

(b) 2019

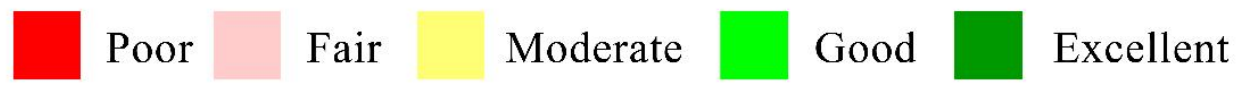

Fig. 6 RSEI classification of the upstream Nansi lake

Moreover, the ecological environment level of the lake grades from excellent or good to moderate. Underground mining activity is probably the main reason, three mines including Binhu, Xin'an, and is detrimental to biodiversity, ecological environment, and ecological function.

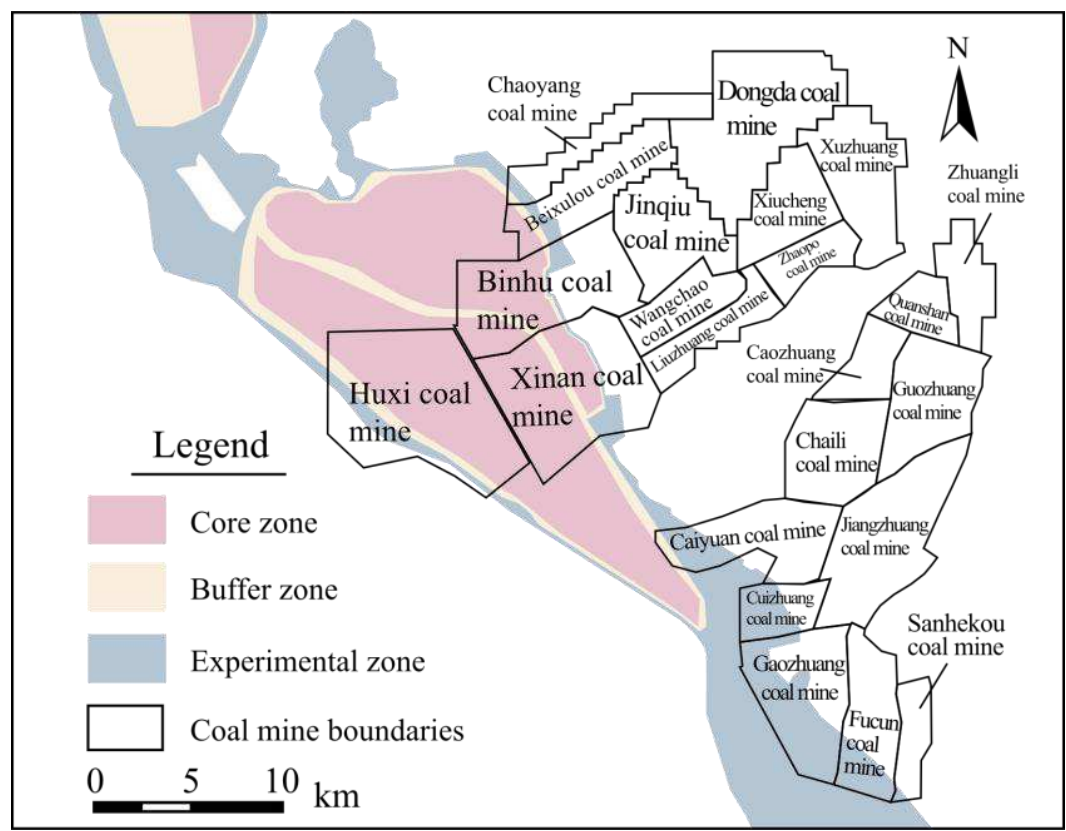


Table 3 Overview of some mines in the research area

\begin{tabular}{|c|c|c|c|c|}
\hline Coal Field & Mine & $\begin{array}{l}\text { Location relationship with the } \\
\text { lake }\end{array}$ & $\begin{array}{c}\text { Production time } \\
\text { (year) }\end{array}$ & $\begin{array}{c}\text { Design production } \\
\text { capacity } \\
\left(1 \times 10^{4} \mathrm{t} / \mathrm{year}\right)\end{array}$ \\
\hline \multirow{10}{*}{ Tengbei } & Binhu & lakeside and under the lake & 2005 & 1.10 \\
\hline & Xin'an & lakeside and under the lake & 1998 & 3.53 \\
\hline & Huxi & lakeside and under the lake & 2001 & 0.90 \\
\hline & Beixulou & lakeside and under the lake & 1996 & 0.45 \\
\hline & Chaoyang & lakeside & 2003 & 0.45 \\
\hline & Jinqiu & lakeside & 2005 & 0.45 \\
\hline & Wangchao & lakeside & 1994 & 0.30 \\
\hline & Liuzhuang & lakeside & 1993 & 0.60 \\
\hline & Dongda & other & 1995 & 0.45 \\
\hline & Zhaopo & other & 1991 & 0.50 \\
\hline \multirow{7}{*}{ Tengbei } & Cuizhuang & lakeside and under the lake & 1993 & 0.60 \\
\hline & Gaozhaung & lakeside and under the lake & 1997 & 3.20 \\
\hline & Fucun & lakeside and under the lake & 1998 & 2.70 \\
\hline & Sanhekou & lakeside and under the lake & 1992 & 0.60 \\
\hline & Caiyuan & lakeside and under the lake & 1982 & 0.30 \\
\hline & Jiangzhuang & lakeside & 1988 & 1.50 \\
\hline & Chaili & lakeside & 1964 & 1.80 \\
\hline
\end{tabular}

The RSEI result of 2019 is less than that of other years in the excellent level, and then the maximum appears in the moderate level, which is higher than that of other years (Fig. 8). In addition, the excellent level area decreases by $18.0 \%$ from 1988 to 2019 . The good level area increases significantly in 2009 but decreases by $103.713 \mathrm{~km}^{2}$ in 2019 compared to 2009 (Table 4). The trend of the moderate level area is similar to the good level, the decreased area is inapparent in 2019. The fair level area is maximum in 1998, and the area of 2019 is basically similar to 1988 . The trend of poor 
270 level area decreases from 1988 to 2009 , and then the area increases by $101.782 \mathrm{~km}^{2}$ between 2009 and 271 2019. Compared with 2009, the ecological quality of 2019 is worse. The reason for this change is due 272 to large-scale underground mining.

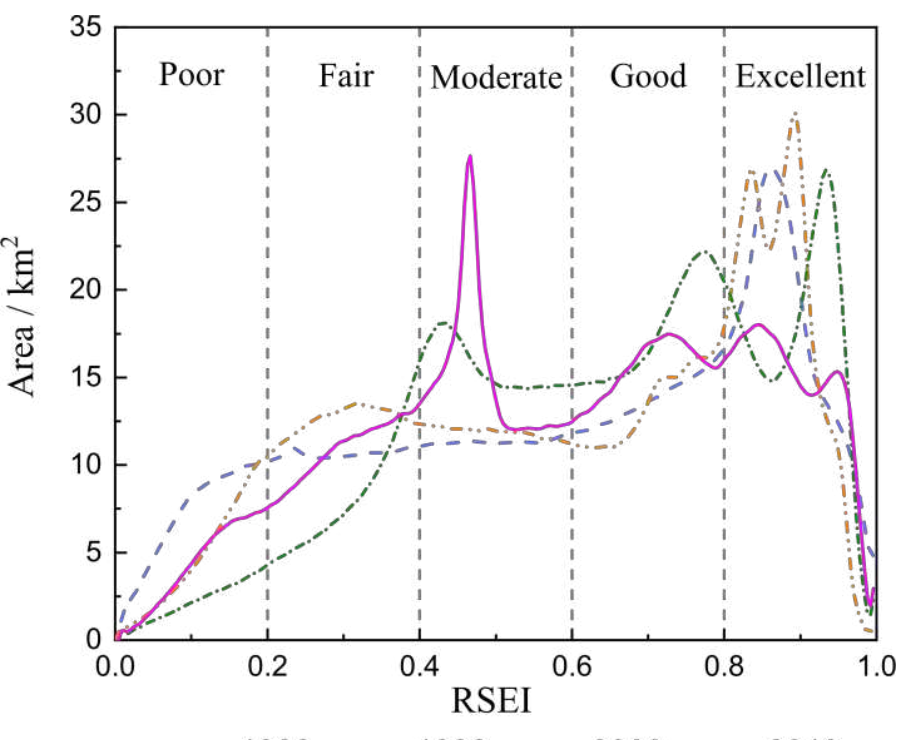

Table 4 Area of each ecological level and proportion

\begin{tabular}{|c|c|c|c|c|c|c|c|c|}
\hline \multirow{3}{*}{ RSEI Level } & \multicolumn{2}{|c|}{1988} & \multicolumn{2}{|c|}{1998} & \multicolumn{2}{|c|}{2009} & \multicolumn{2}{|c|}{2019} \\
\hline & Area & Proportion & Area & Proportion & Area & Proportion & Area & Proportion \\
\hline & $\left(\mathrm{km}^{2}\right)$ & $(\%)$ & $\left(\mathrm{km}^{2}\right)$ & $(\%)$ & $\left(\mathrm{km}^{2}\right)$ & $(\%)$ & $\left(\mathrm{km}^{2}\right)$ & $(\%)$ \\
\hline Poor $(0 \sim 0.2)$ & 352.660 & 11.558 & 231.710 & 7.594 & 106.156 & 3.479 & 207.938 & 6.815 \\
\hline Fair $(0.2 \sim 0.4)$ & 540.141 & 17.703 & 641.314 & 21.019 & 408.193 & 13.379 & 551.358 & 18.071 \\
\hline Moderate $(0.4 \sim 0.6)$ & 575.793 & 18.872 & 606.455 & 19.877 & 794.147 & 26.028 & 772.188 & 25.308 \\
\hline Good (0.6 0.8) & 693.689 & 22.736 & 686.372 & 22.496 & 894.654 & 29.322 & 790.941 & 25.923 \\
\hline Excellent (0.8 1.0) & 888.834 & 29.131 & 885.265 & 29.014 & 847.967 & 27.792 & 728.692 & 23.883 \\
\hline
\end{tabular}

Fig. 8 RSEI variation of the upstream Nansi lake

\section{Conclusions}

282 the lake area is extracted by the SVM classifier of spectral and geometric texture information. 
283 Moreover, four indexes of RSEI (greenness, humidity, dryness, and heat) are used to assess ecological environment quality with the PCA analysis method, which can avoid artificial subjective defects.

The change of the lake water area has little relation with underground mining but is related to the annual precipitation. According to estimate, the subsidence volume of the lake bottom will be $1.94 \times 10^{9}$ water may no longer exist. $\mathrm{m}^{3}$ after accomplish mining of Tengnan and Tengbei coal fields, but the lake storage capacity is only $9.03 \times 10^{8} \mathrm{~m}^{3}$, namely that most of the lake water will flow into the subsidence area, and the shallow

The area of deteriorating ecological environment is located in Tengnan and Tengbei coal fields. Vegetation coverage decreases (reduction of greenness and wetness; increase of dryness and heat) due to surface subsidence, gangue, and drainage. On the one hand, the deteriorating ecological quality of the lake area is mainly affected by mining activities including Huxi, Xin'an, and Binhu coal mines. The deteriorating ecological quality of the non-lake area is mostly influenced by Jinqiu, Wangchao, and Dongda coal mines. On the other hand, the area of improved ecological environment is located in the northeastern hilly area, which attributes the success to afforestation and other beneficial activities of improving soil erosion.

Finally, coal mines need to apply more environmentally friendly mining method for protecting the lake ecological environment, and actively participate in ecological restoration. Moreover, the coal mines from the natural reserve may be closed or limited to the mining boundary.

\section{Acknowledgments}

\section{Consent to Participate}

All the authors agree to participate in this research. 


\section{Consent to Publish}

315 All the authors agree to publish the manuscript research.

\section{Authors Contributions}

318 Hu Liu: writing, calculation, and visualization

319 Yan Jiang: funding support, writing- reviewing and editing

320 Rafal Misa: model research, modification of the text, and discussion

321 Junhai Gao: project support, and scientific advice

322 Mingyu Xia: remote sensing data processing

323 Axel Preusse: providing scientific advice and reviewing

324 Anton Sroka: providing scientific advice and reviewing

325 Yue Jiang: providing research plan, remote sensing data processing, writing- reviewing and editing

\section{Funding}

This research work was financially supported by the Alexander von Humboldt Foundation 329 (CHN/1101176STP), National Research and Development Project (2016YFC0501105), and China 330 Coal Technology \& Engineering Group Project (2018-TD-MS052).

\section{Availability of data and materials}

All data generated or analysed during this study are included in this manuscript.

\section{Conflict of Interest}

The authors declare no conflict of interest.

\section{References}

339 China MEE (2015) Technical Criterion for Ecosystem Status Evaluation vol HJ 192-2015. China Environmental Press, Beijing (in Chinese) 
Environment 17:301-306. https://doi.org/10.1016/0034-4257(85)90102-6

Den K, Tan Z, Jiang Y, Dai H, Shi Y, Xu L (2015) Deformation Monitoring and Subsidence Engineering. China University of Mining and Technology Press, Xuzhou (in Chinese)

Du Q, Fowler JE (2007) Hyperspectral Image Compression Using JPEG2000 and Principal Component Analysis. IEEE Geoscience and Remote Sensing Letters 4:201-205.https://doi.org/10.1109/LGRS.2006.888109

Ge XL, Liu J, Wang RQ (2012) The Comparison between the Historical and Current Vegetation in Nansi Lake Area. Advanced Materials Research 518-523:5180-5184.https://doi.org/10.4028/www.scientific.net/AMR.518523.5180

Gold C, Sollich P (2003) Model selection for support vector machine classification. Neurocomputing 55:221-249. https://doi.org/10.1016/S0925-2312(03)00375-8

Huang C, Wylie B, Yang L, Homer C, Zylstra G (2002) Derivation of a tasselled cap transformation based on Landsat 7 at-satellite reflectance. International Journal of Remote Sensing 23:17411748.https://doi.org/10.1080/01431160110106113

Jiang Y, R.MISA, Li P, Yuan X, A.Sroka, Jiang Y (2019) Summary and Development of Mining Subsidence Theory. Metal Ming 10:1-7.https://doi.org/10.19614/j.cnki.jsks.201910001 (in Chinese)

Kratzsch H (1974) Mining subsidence engineering. Springer-Verlag, Berlin

Li M, Jiang M (2003) Effect of Coal-mining to Environment in Nansihu Area. Shandong Land and Resources 05:2831 (in Chinese)

Liang CL (2014) NDVI Changes of the Nansi Lake in Shandong Province of China. Advanced Materials Research 919-921:1659-1662.https://doi.org/10.4028/www.scientific.net/AMR.919-921.1659

Ma L, Guo J, Liu W, Zhang D, Yu Y (2019) Water Conservation when Mining Multiple, Thick, Closely-Spaced Coal Seams: A Case Study of Mining Under Weishan Lake. Mine Water and the Environment 38:643657.https://doi.org/10.1007/s10230-019-00610-8

Meng L, Dong J (2019) LUCC and Ecosystem Service Value Assessment for Wetlands: A Case Study in Nansi Lake, China. Water 11:1597.https://doi.org/10.3390/w11081597

Nichol J (2005) Remote sensing of urban heat islands by day and night. Photogrammetric Engineering \& Remote Sensing 71:613-621.https://doi.org/10.14358/PERS.71.5.613

Reddish D, Whittaker B (1989) Subsidence: occurrence, prediction and control. Elsevier, Amsterdam

Rikimaru A, Roy P, Miyatake S (2002) Tropical forest cover density mapping. Tropical ecology 43:39-47

Shu K (1992) Experiment and research on coal mining under Weishanhu Lake. Coal Science and Technology 07:44- 
49.https://doi.org/10.13199/j.cst.1992.07.45.shuksh.013 (in Chinese)

Sobrino JA, Jiménez-Muñoz JC, Paolini L (2004) Land surface temperature retrieval from LANDSAT TM 5. Remote

Sui WH, Xu ZM Risk Assessment for Coal Mining Under Sea Area. In, Berlin, Heidelberg, 2013. New Frontiers in Engineering Geology and the Environment. Springer Berlin Heidelberg, pp 199202.https://doi.org/10.1007/978-3-642-31671-5_35

Teng Y, Gao D, Zhu W (2012) Coal Mining under Water. China Coal Industry Publishing House, Beijing (in Chinese)

Todd SW, Hoffer RM (1998) Responses of spectral indices to variations in vegetation cover and soil background. Photogrammetric Engineering and Remote Sensing 64:915-921

Wang W, Liu X, Wang Y, Guo X, Lu S (2016) Analysis of point source pollution and water environmental quality variation trends in the Nansi Lake basin from 2002 to 2012. Environmental Science and Pollution Research 23:4886-4897.https://doi.org/10.1007/s11356-015-5625-x

$\mathrm{Xu} \mathrm{H}$ (2008) A new index for delineating built-up land features in satellite imagery. International Journal of Remote Sensing 29:4269-4276.https://doi.org/10.1080/01431160802039957

Xu ZM, Sui WH Statistical Prediction of Overburden Failure Due to Coal Mining Under Sea Area. In, Berlin, Heidelberg, 2013. New Frontiers in Engineering Geology and the Environment. Springer Berlin Heidelberg, pp 255-258.https://doi.org/10.1007/978-3-642-31671-5_46

Zhang D, Sui W, Liu J (2018) Overburden Failure Associated with Mining Coal Seams in Close Proximity in Ascending and Descending Sequences Under a Large Water Body. Mine Water and the Environment 37:322335.https://doi.org/10.1007/s10230-017-0502-0

Zhou ZC, Shangguan ZP, Zhao D (2006) Modeling vegetation coverage and soil erosion in the Loess Plateau Area of China. Ecological Modelling 198:263-268. https://doi.org/10.1016/j.ecolmodel.2006.04.019 


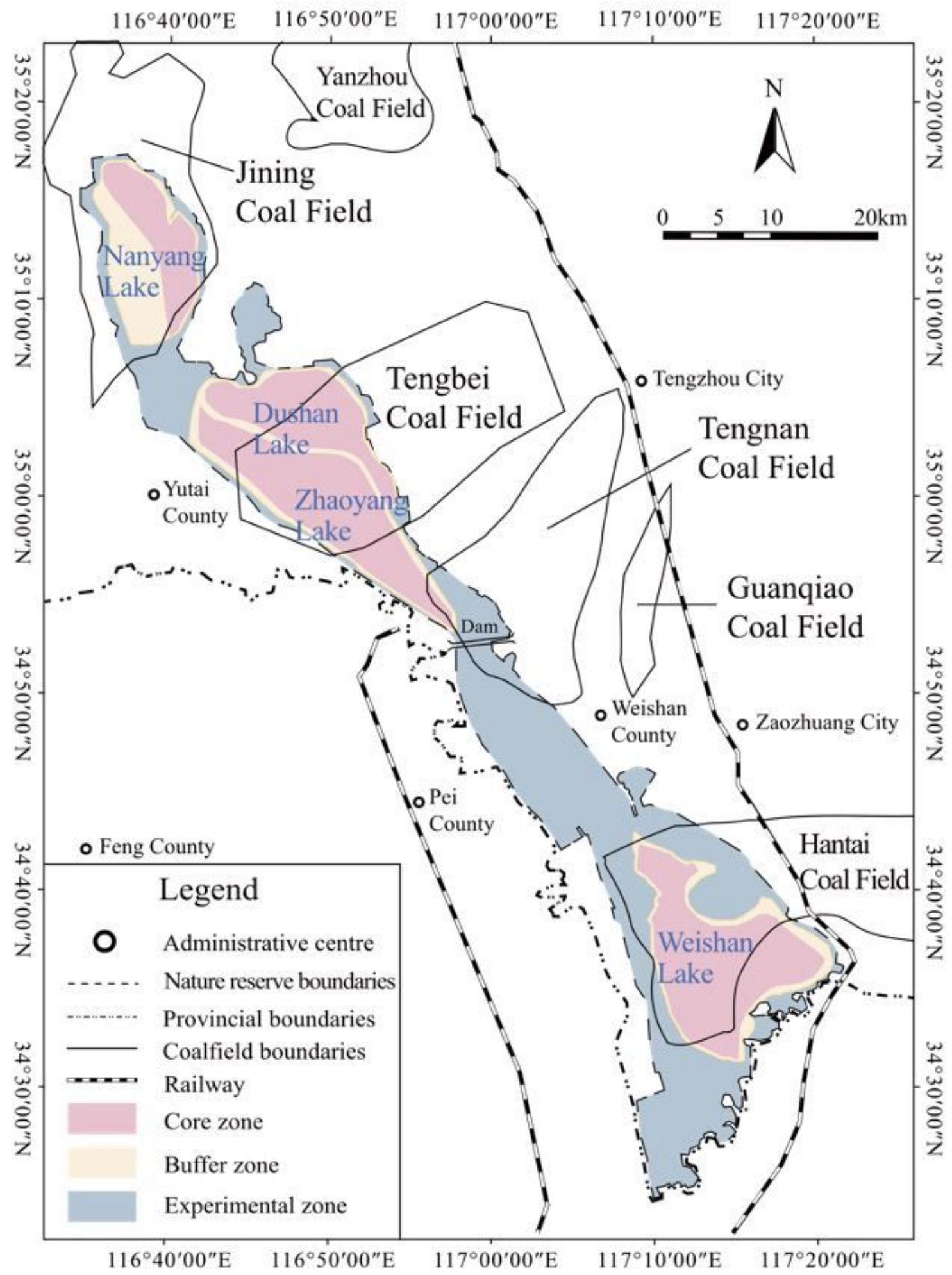

Figure 1

Distribution of Nansi lake nature reserve and coal resources Note: The designations employed and the presentation of the material on this map do not imply the expression of any opinion whatsoever on the part of Research Square concerning the legal status of any country, territory, city or area or of its 
authorities, or concerning the delimitation of its frontiers or boundaries. This map has been provided by the authors.

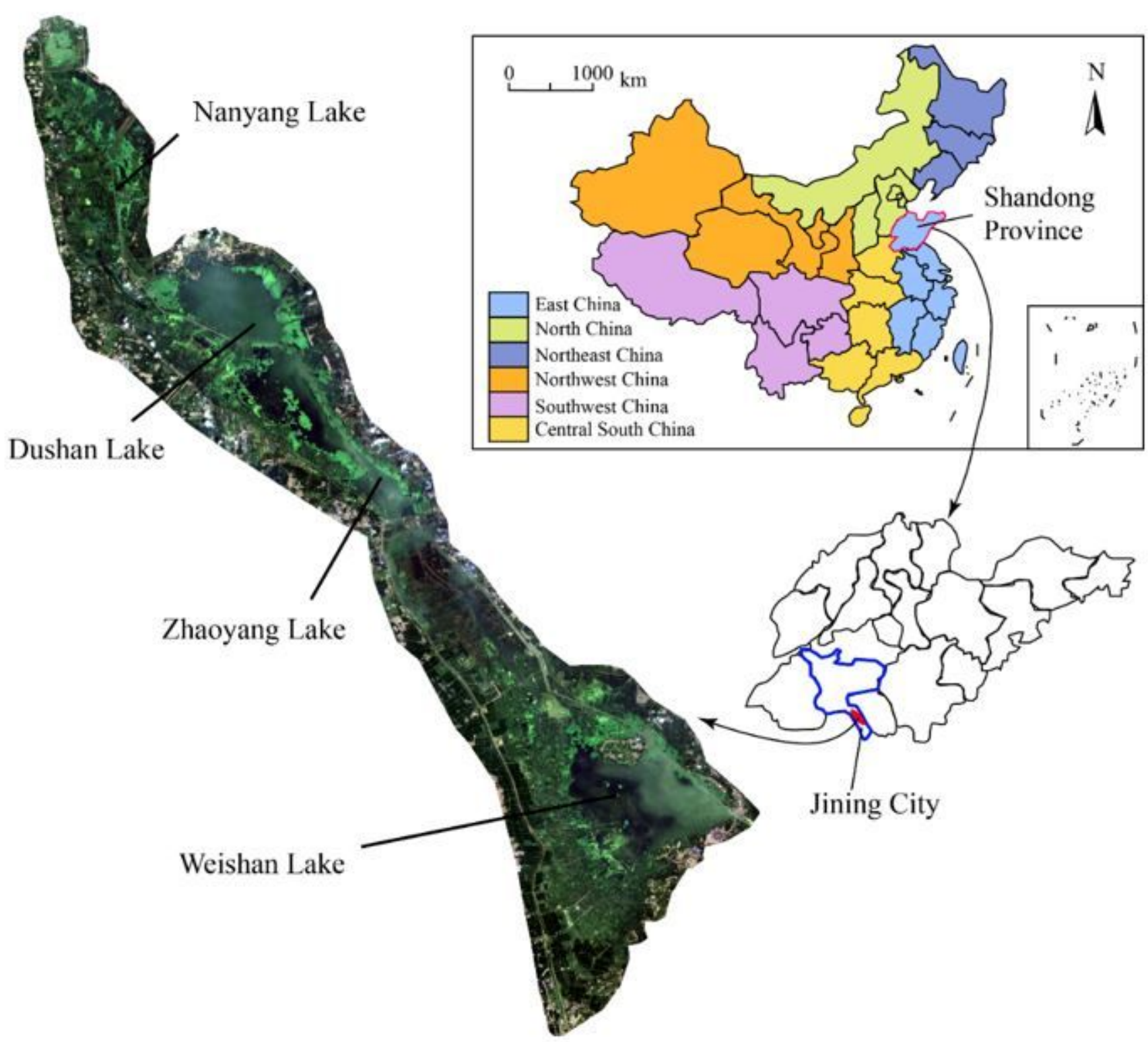

\section{Figure 2}

Location of Nansi Lake (2019 Landsat-8 OLI image) Note: The designations employed and the presentation of the material on this map do not imply the expression of any opinion whatsoever on the part of Research Square concerning the legal status of any country, territory, city or area or of its authorities, or concerning the delimitation of its frontiers or boundaries. This map has been provided by the authors. 


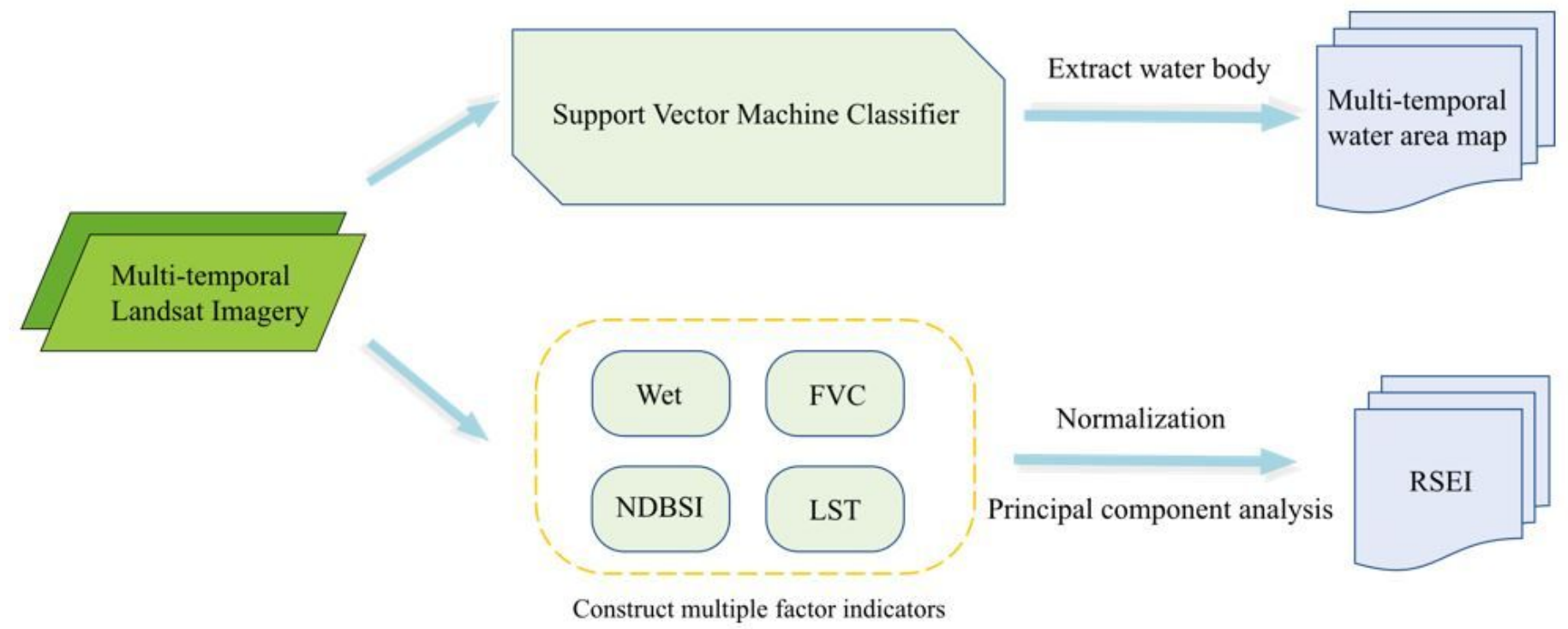

Figure 3

Research method route 


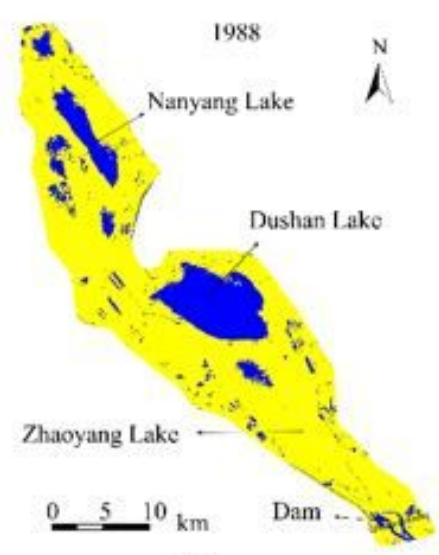

(a)

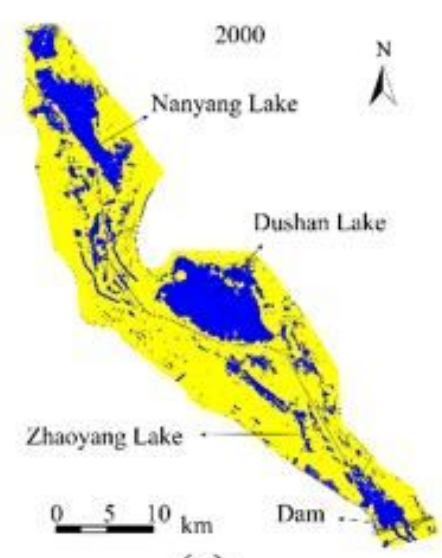

(e)

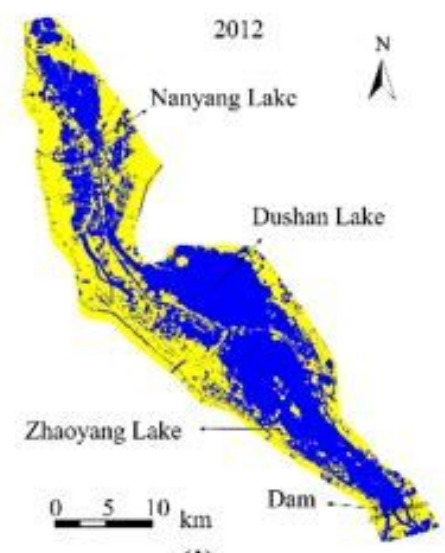

(i)

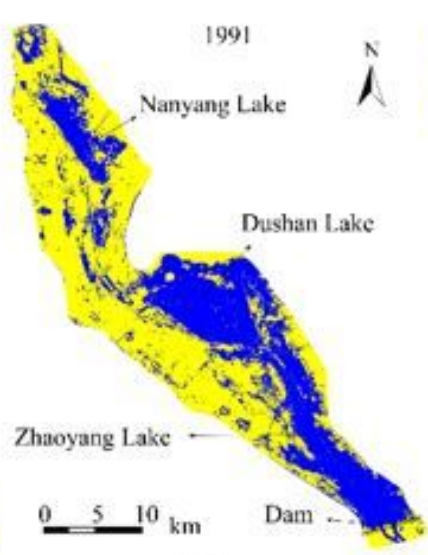

(b)

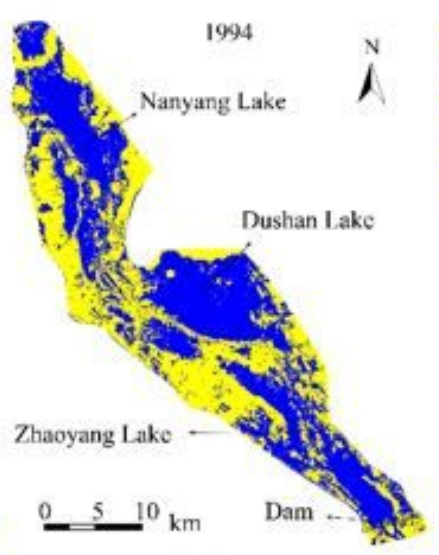

(c)

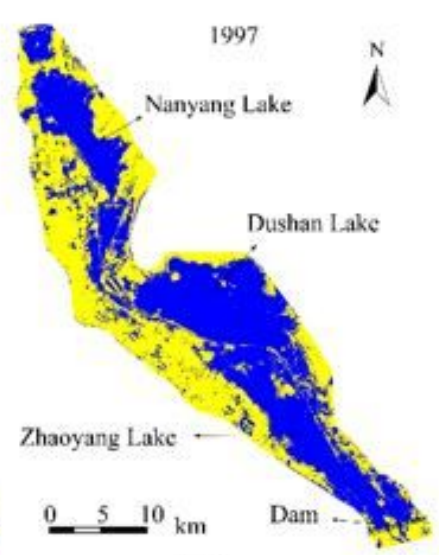

(d)

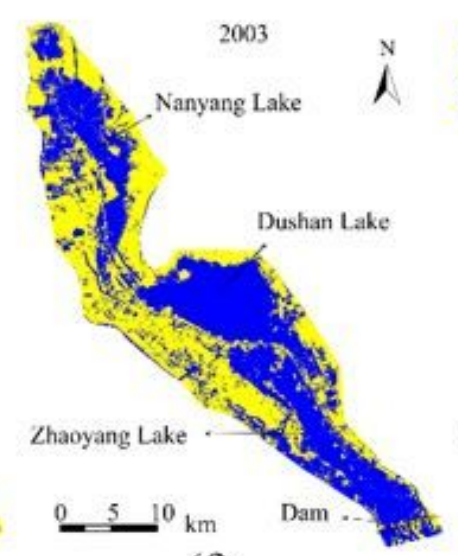

(f)

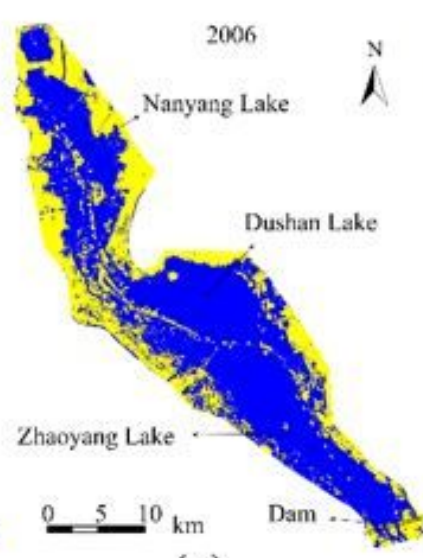

(g)

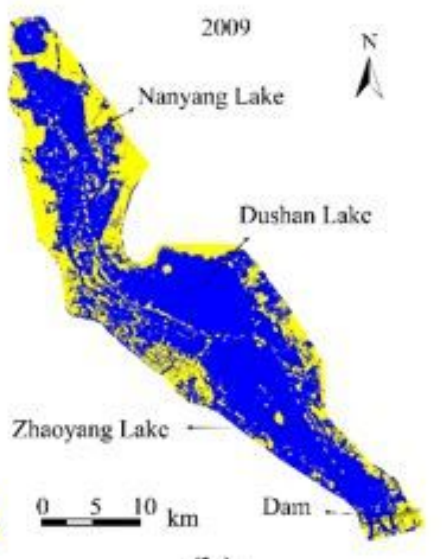

(h)

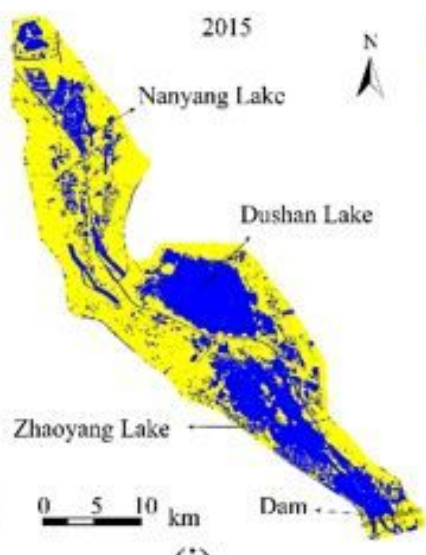

(j)

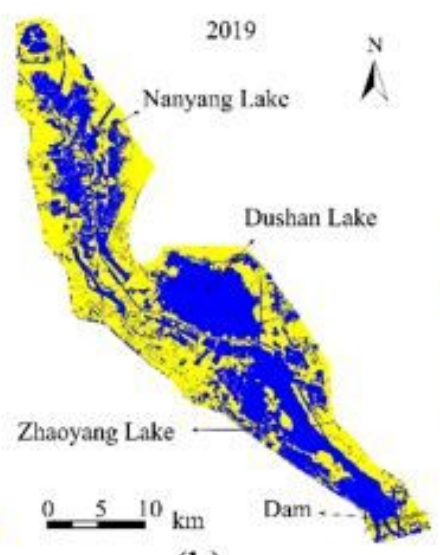

(k)

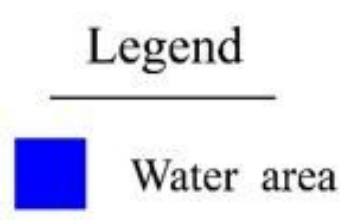

Others

\section{Figure 4}

Variation characteristics of the upstream Nansi lake Note: The designations employed and the presentation of the material on this map do not imply the expression of any opinion whatsoever on the part of Research Square concerning the legal status of any country, territory, city or area or of its authorities, or concerning the delimitation of its frontiers or boundaries. This map has been provided by the authors. 


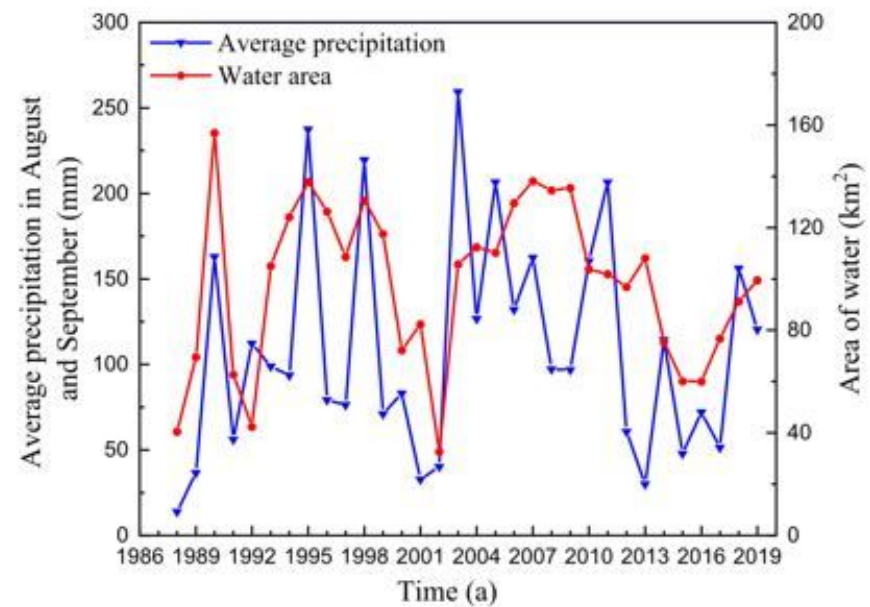

(a) Nanyang Lake

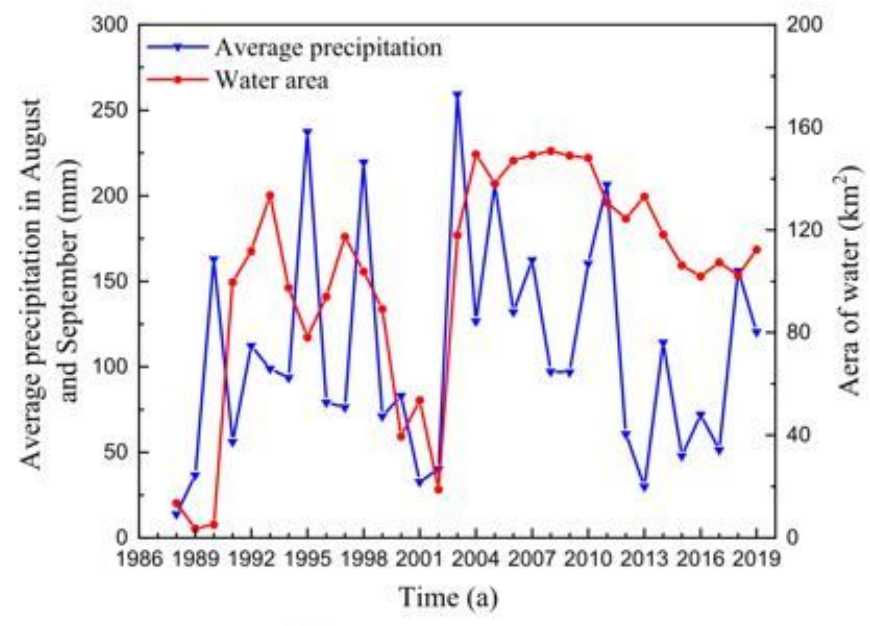

(c) Zhaoyang Lake

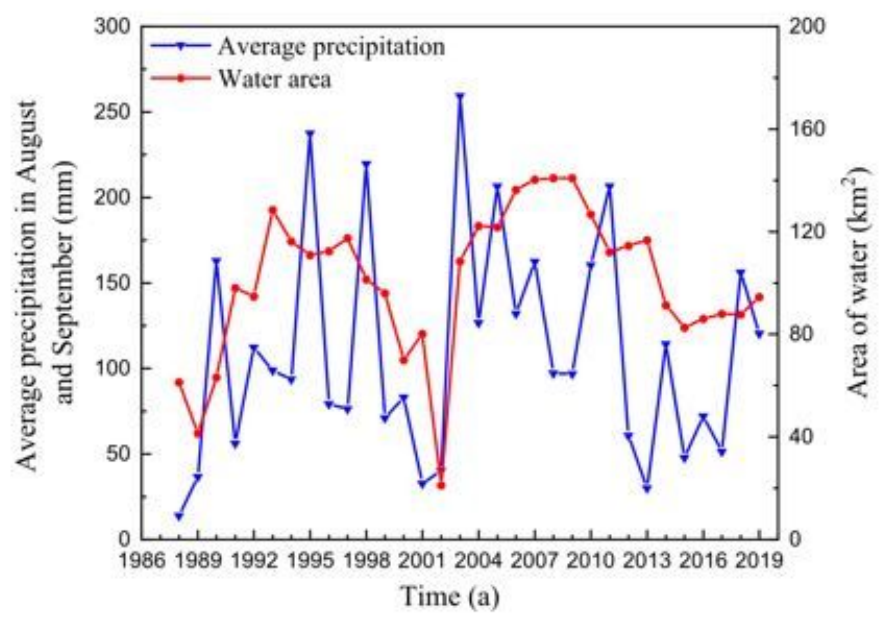

(b) Dushan Lake

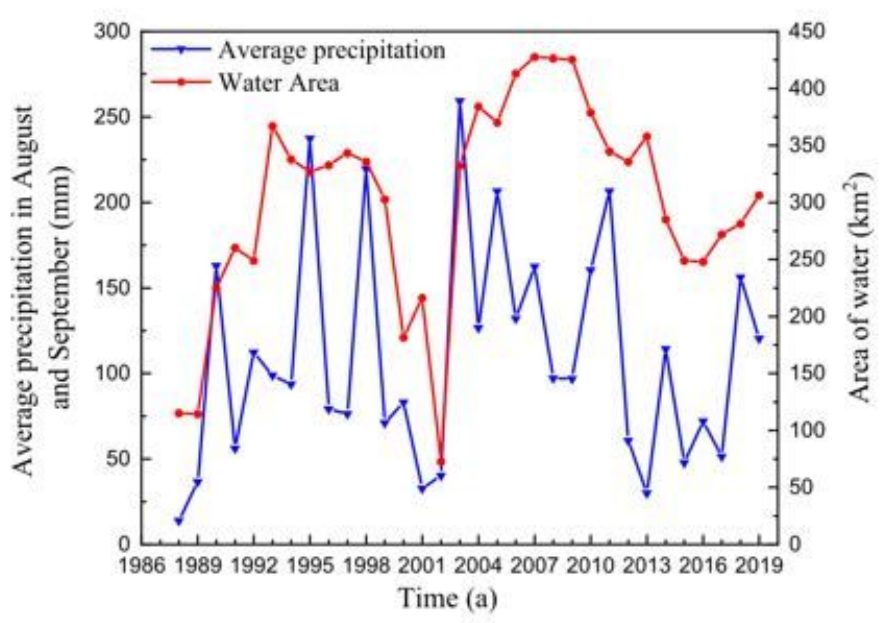

(d) The Upstream Lake

Figure 5

The trends of water area and average precipitation 


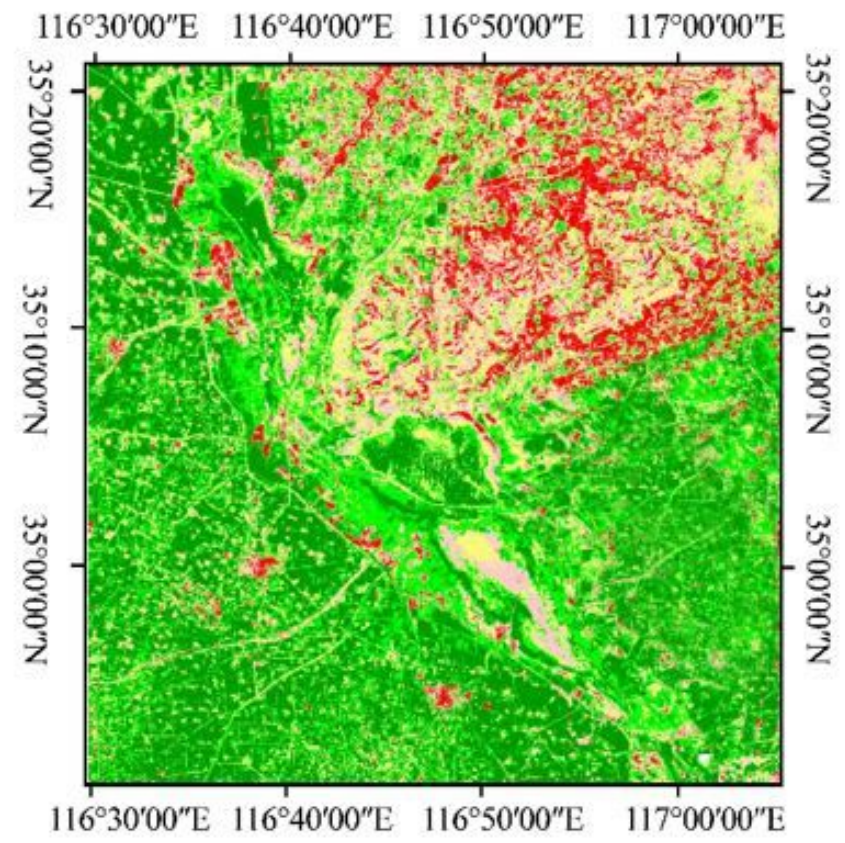

(a) 1988

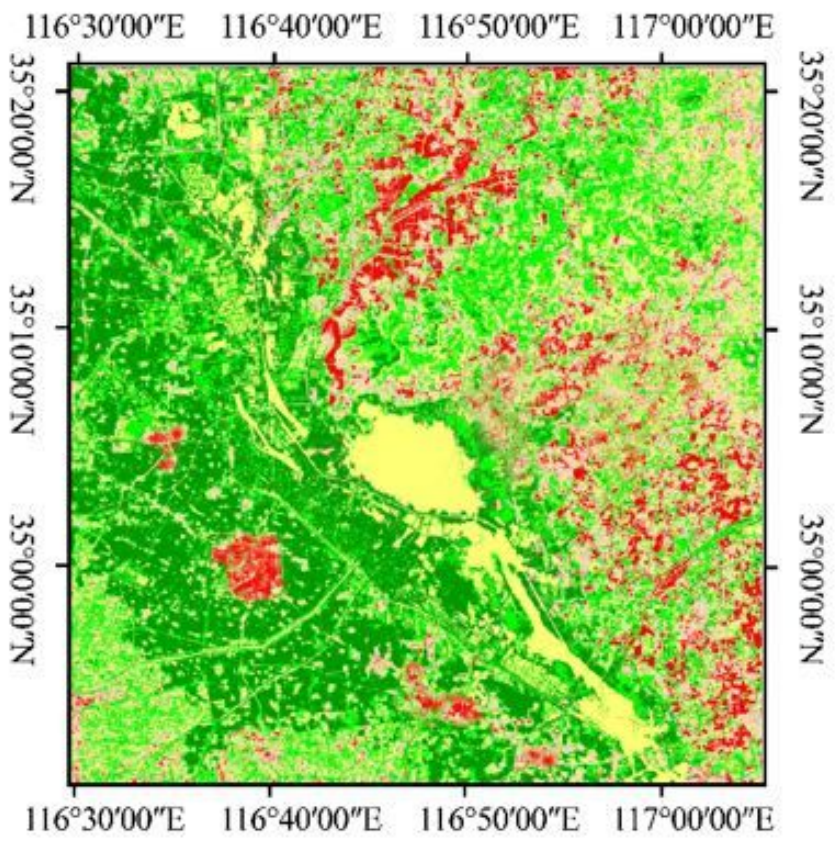

(b) 2019

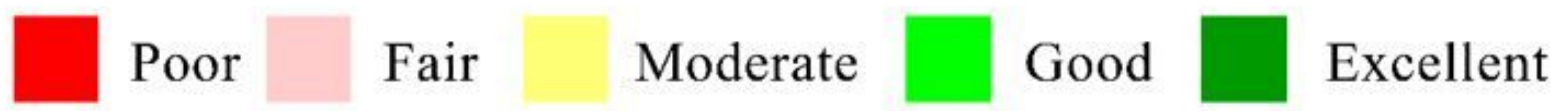

\section{Figure 6}

RSEI classification of the upstream Nansi lake Note: The designations employed and the presentation of the material on this map do not imply the expression of any opinion whatsoever on the part of Research Square concerning the legal status of any country, territory, city or area or of its authorities, or concerning the delimitation of its frontiers or boundaries. This map has been provided by the authors. 


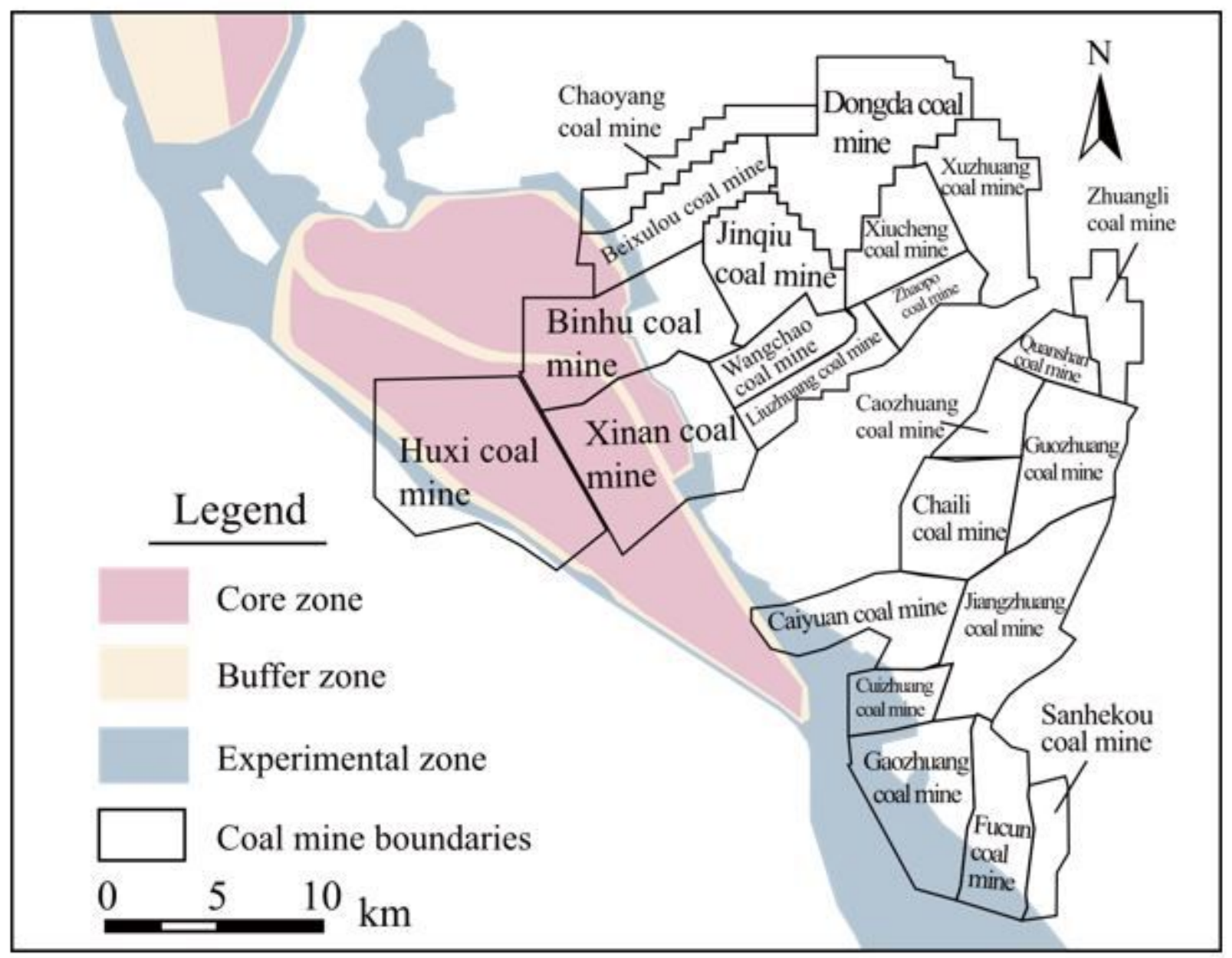

\section{Figure 7}

Distribution of mines around the upstream Nansi lake Note: The designations employed and the presentation of the material on this map do not imply the expression of any opinion whatsoever on the part of Research Square concerning the legal status of any country, territory, city or area or of its authorities, or concerning the delimitation of its frontiers or boundaries. This map has been provided by the authors. 


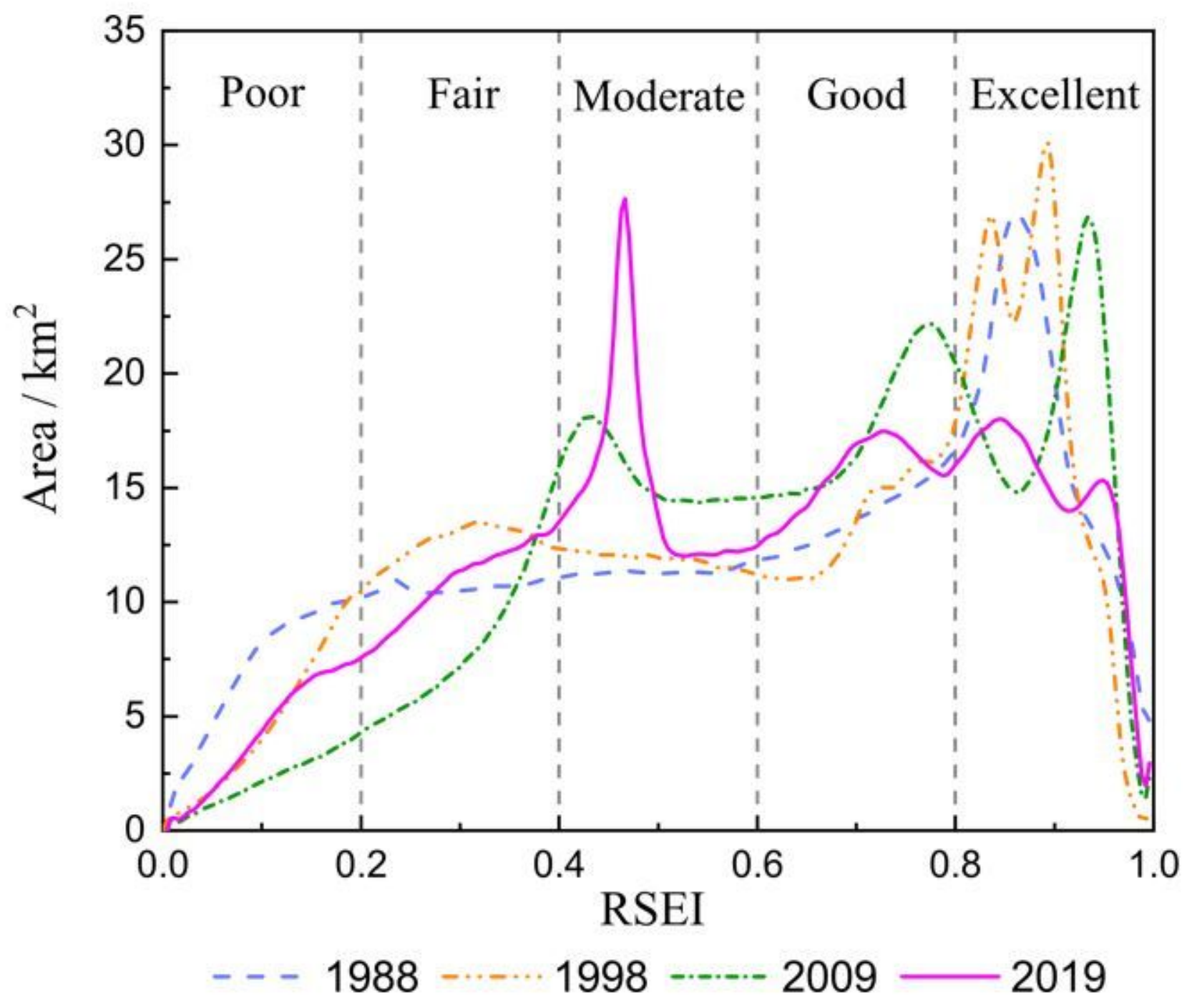

Figure 8

RSEl variation of the upstream Nansi lake 